\title{
Psychotherapy for Munchausen syndrome by proxy
}

\author{
A R NICOL AND M ECCLES \\ Nuffield Psychology and Psychiatry Unit and Department of Child Health, Royal Victoria Infirmary, \\ Newcastle upon Tyne
}

SUMmaRY The management of a case of Munchausen syndrome by proxy is described. Possible indications for individual interpretive psychotherapy in child abuse are given.

Many different forms of psychotherapy have been tried for child abuse-behaviour modification, ${ }^{1}$ focused social casework ${ }^{2}$ and anger management. ${ }^{3}$ Desensitisation and family therapy techniques also have their advocates. Since child abuse is most usefully regarded as a symptom that may accompany a spectrum of individual or family disorders, a range of therapies may be appropriate to match the variety of different problems. In Munchausen syndrome by proxy mothers fabricate false symptoms and signs over long periods so causing their children innumerable harmful investigations, treatments, and other procedures. ${ }^{4}$ It is a form of abuse likely to stir up particularly strong emotions among doctors since they are, in a sense, active participants. In this paper we report such a case where the less commonly employed individual interpretative therapy for the mother proved helpful. In this case two children in one family had presented with fictitious illness, the youngest to an extent that was a repeated threat to life.

\section{Paediatric presentation}

This child was the youngest of four, and the only daughter. Her father was aged 31 and a manager; her mother was a 30 year old housewife. Both parents were deeply involved with their local church and mother made frequent mention of her religious beliefs. The two elder boys, 9 and 7 years old, had not been involved in any problems but the third son, 3 years old, had IgA deficiency, had been treated for an irritable hip and, at the time of his sister's presentation, was about to be invasively investigated for haematuria, which subsequently vanished.

Mother's pregnancy with our patient was complicated by a threatened miscarriage at 12 weeks and an antepartum haemorrhage associated with hypertension at 36 weeks. Labour was induced at 38 weeks after a fortnight of bedrest. The infant weighed $2.9 \mathrm{~kg}$ and became jaundiced after birth. Her neonatal period was otherwise unremarkable. Breast feeding was terminated at five weeks because of cracked nipples.

Her first admission to hospital was at the age of 10 weeks when she presented with a four day history of diarrhoea and a one day history of vomiting. She seemed apathetic and dehydrated and was admitted along with her mother who stayed with her throughout this and each of her subsequent admissions. Her serum sodium value was $163 \mathrm{mmol} / \mathrm{l}$ and with a diagnosis of hypernatraemic dehydration she was resuscitated with whole blood and normal saline. A normal feeding pattern was difficult to re-establish but she eventually settled.

During the subsequent 12 months the child had a further 11 admissions to the same ward. The history was always of a variable degree of diarrhoea and vomiting. Accompanying problems included symptoms of upper respiratory tract infection, variable polyuria, eczema, unexplained nocturnal hypothermia, peripheral oedema, and an attack of measles proved by virus isolation. Continued diarrhoea both at home and in hospital, with varying amounts of sugar in her stools prompted progressive removal of food items from her diet until she was receiving a diet free from lactose, sucrose, and glucose, with beef, chicken, cauliflower and broccoli as her only tolerated solids. A second raised serum sodium concentration of $160 \mathrm{mmol} / \mathrm{l}$ prompted urine analysis and on three occasions she had urinary sodium concentrations of over $300 \mathrm{mmol} / \mathrm{l}$.

Urine specimens were unusually difficult to obtain as bags leaked or became detached with striking regularity. The diagnosis of salt poisoning was eventually proved when $13 \mathrm{ml}$ of vomitus, obtained shortly after her last admission, was shown to have a sodium content of $660 \mathrm{mmol} / \mathrm{l}$ (approximately 10 times the normal value).

The girl spent a total of 29 weeks in hospital, $43 \%$ 
of her life by the time she was finally discharged (see Figure). She had been subjected to two computed tomograms of the head (one unsuccessful), two blood transfusions, three radiographs, one electroencephalograph, 51 stool specimens (all negative), and 83 venepunctures. Ward staff had been struck by mother's regular presence on the ward. Even when her child was not an inpatient she would visit other children. Nurses noted that she remained aloof and avoided eye contact. Her handling of the baby was technically competent but rather cold.
Mother and father were confronted with the diagnosis in a joint meeting with the paediatrician in charge of the case. Confession came later when she was told of the decision by a case conference convened by the social services department to remove the child to foster care. It was clear that father had no idea what had been going on. The child was readmitted to the ward and within two weeks her diet had returned to normal. She had no more diarrhoea or vomiting and achieved a striking weight gain (see Figure). The gross motor develop-

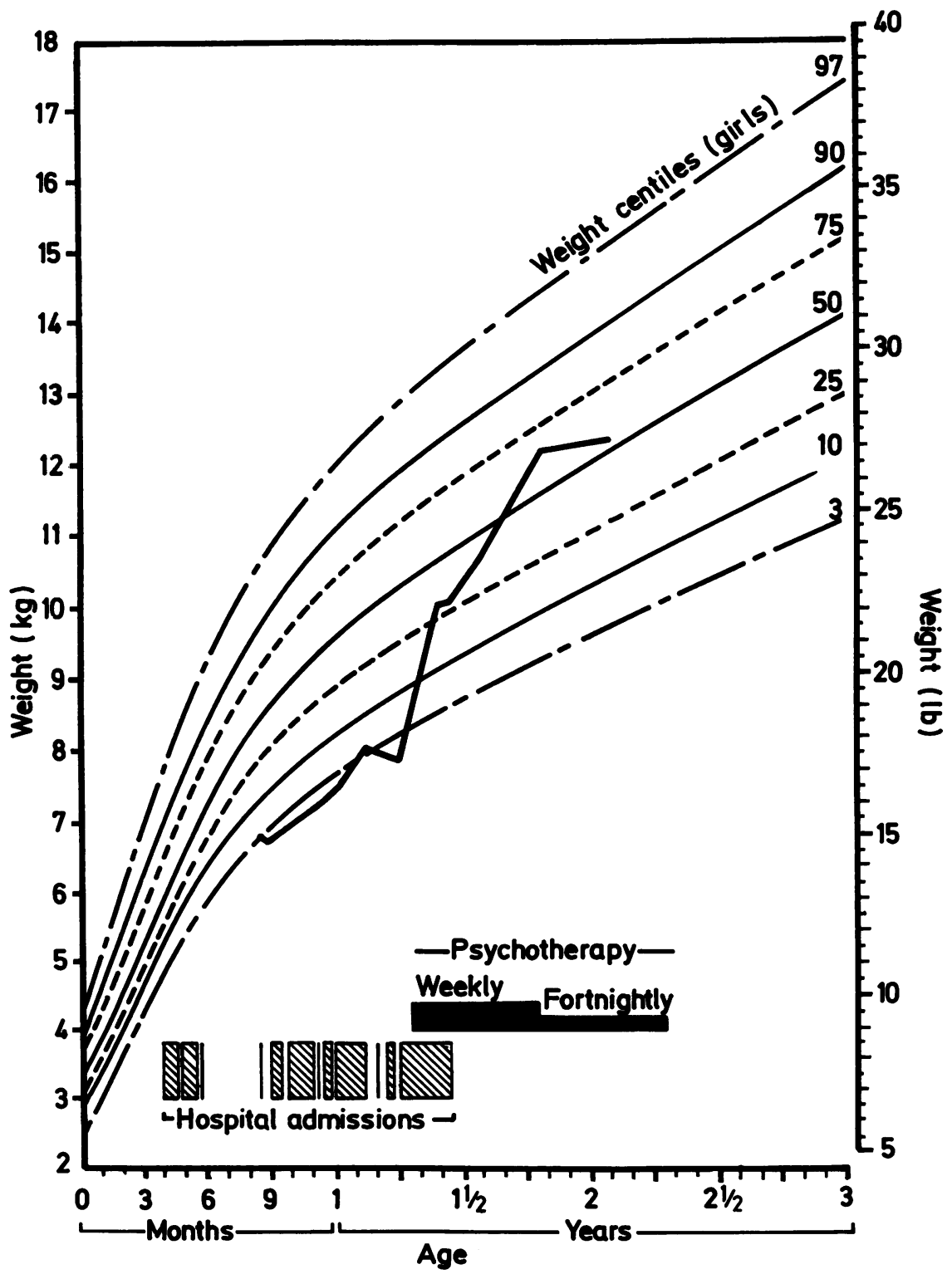

Figure Timetable of events in relation to patient's weight. 
ment, which had been four months retarded, made a rapid return to normal.

The family doctor confirmed that mother was a very frequent attender at the surgery with a multitude of complaints. He recognised that her attitude to her daughter was abnormal; for example on occasions she seemed to know when the child would return to hospital. She was known to be unpopular in the local community, although the reasons for this were not very clear.

\section{Psychiatric assessment}

Before the confession a child psychiatrist was asked to assess the family. At interview mother presented as tense and tight lipped. She vehemently denied any allegations of involvement in dosing her daughter with salt. She gave a detailed description of the problems of the food allergy and said that she had been astounded when the paediatrician had suggested she came to the doctor too much-didn't her children have food allergy and immune deficiency? She reported, but minimised, two psychiatric problems; the fact that she had been on antidepressant drugs at the time of her daughter's birth, and her father's alcoholism. At the time of interview there was no clinical depression or other mental illness.

\section{Assessment for psychotherapy}

In view of the dangerous nature of the disorder ${ }^{4}$ it was thought at first that the child should be removed from the family and brought up in an alternative home. When mother confessed, it was decided that since she had admitted that there was a problem, treatment was now a possibility. The matter was taken to the magistrates court where the medical, psychiatric, and social work recommendations were unanimous. These were that a care order should be made but that the child should be returned home under very strict social work and health visitor supervision. As an essential part of the package a trial of psychotherapy was undertaken. The aim was to assess whether the mother could benefit from a rather long term supportive therapy which would fulfil her dependency needs and discourage further inappropriate medical consultation.

The child psychiatrist also appeared as an expert witness at court, this being seen as a unique opportunity to emphasise to the mother the gravity of the situation and its root in her emotional difficulties.

After a few sessions of therapy it became clear that the mother had a strong wish to understand herself, that she was intelligent, and that she had a capacity to bring active and painful feelings to therapy sessions. For these reasons a more active and a deeper form of interpretive therapy was undertaken. This continued on a weekly basis for six months and fortnightly for a further six months. At this point there was a clear termination of therapy although family supervision by the social worker and health visitor continued. All the psychotherapy was undertaken by one child psychiatrist (ARN).

\section{Some general themes of therapy}

Presentation. The mother came to therapy sessions looking well and attractive. She was always on time and seemed glad to see the therapist. The sessions were often emotionally charged and there were very few silences. The patient often brought the outcome of thoughts during the week, 'I've been working it out . . .' indicating that the sessions continued in her mind for many hours outside their formal limits.

The reason for the abuse. This emerged as complex. On the surface she said: 'I liked the sympathy, I needed my daughter to be ill so that I was important. I felt I was somebody in the ward.' Having initiated the deception, other factors came into play, she felt the need to keep up the fiction of the baby's illness. She derived much pleasure from the contact with the doctors. 'They were intelligent, I liked to feel that I was being considered by intelligent people.' She also described far less complimentary feelings- she had found the doctors dithering and took considerable pleasure in having outwitted them for so long. Full realisation of the danger she had put her child in emerged gradually.

Affective expression in therapy. The emotional experience of therapy is most important. There were two affective states which emerged as particularly important in this therapy: remorse and something that the patient called 'depression'. Remorse was intense in early sessions and tended to resurface throughout the year: 'It's awful to think but . . . I put the harm I was doing to the back of my mind.' The full enormity of her actions first struck her when her solicitor told her that the paediatrician's court report said that she had Munchausen syndrome by proxy. The court case was painful but also helped. At one point at a later stage in therapy and after a particularly charged session she reported lying awake at night contemplating in full measure the damage she had done. She had to search for ways of checking that she would never again get into a situation where she could act in such a manner. For this reason she searched for clues as to the cause of her behaviour, and needed, so she said, to seek her 
husband's and friends' reassurance that they would tell her if she seemed to be reverting to her old ways. For many months she did not go to her doctor at all, facing great anxiety when her children had minor ailments. Eventually, and after a change of general practitioner she did resume appropriate contact. She was not totally wracked with self blame, being able to recognise insensitive handling by some authority figures for what it was. She grumbled about the inertia of the care proceedings. She also frequently complained of 'depression'. Apart from the fact that this mood state was unpleasant, it was not easy to understand what it consisted of. It certainly was not clinical depression, and was quite different from her appropriate and healthy remorse. As the therapy developed, this 'depression' assumed a central part in the pathogenesis of the abuse. It was a dangerous affect, which seemed to have infantile rage as a central component, together with crushingly low self esteem.

Pathogenesis of the abuse. There can be no doubt that the deception was totally conscious; however it was based on motivations that arose from a deeper disturbance. The patient realised that her family of origin had been built on a pattern of dominance and submission. Dominant family members raged and bullied, singled out favourites and rejects, and took total control of all family decisions. Submissive family members sought 'peace at any price' and withdrew into anxiety and overconcern with health. In the mother's family of origin, father was a selfmade man and a hectoring bully who would retreat to bed for days at a time in a sulk or smash furniture in a rage if he did not get his own way. The mother had been the favoured one as a child because she had shown academic promise and in turn she idolised her father. Her mother was characterised as a timid placating soul, chronically overconcerned with her own and her children's health. There was one younger sister, less favoured and more rebellious, who left the family home for London when she grew up.

Her early promise at school was dashed when, after ' $O$ ' levels, she had left school because of an overwhelming fear of fainting. This was a general social withdrawal, she always found friendship difficult. Subsequently she worked in a local town hall where she met her husband. The fear of fainting persisted but she was able to gain some control of it. Her father was extremely angry at the academic failure as he had hoped she would go to university.

In subsequent years it became clear that her father was feeling the strain of his new responsibilities. His drinking was out of control and eventually he was sacked from work for dangerous driving and shoplifting. The case was heard in the court. This latter event, in particular, had a profound effect on the patient who by this time had three children. It seemed to fracture her fragile idealisation of father. This is the first time she reported feeling 'depressed'. She found, in her general practitioner, a source of support and kindness and this reinforced the pattern of very regular attendance at the surgery by herself and with the children that she had learned from her mother in childhood. It led to the discovery of the IgA deficiency thus giving credence to her behaviour.

Mother remembered being pregnant with her daughter, and the threatened miscarriage, as a time of blood, depression, and alarms which kept going off falsely in the middle of the night. Her 'depression' deepened. When her daughter was born she very much wanted to breast feed and when this failed due to cracked nipples her 'depression' was reinforced, indeed her husband had to feed the baby as she felt too disappointed to do so. It was in this 'depressed' state that she first gave salt to the baby. She was somewhat surprised when her delinquency was not detected immediately. Instead she discovered the pleasures of hospital life.

Religion. There was an opportunity to explore the juxtaposition of her religion with her behaviour. Intelligent though she was, she believed that Christians were simply people who forgave others with the implication that they were morally better than others. Her attitude emerged as simplistic and harsh, her belief impoverished, and her preaching hypocritical when placed alongside her behaviour to her daughter. In therapy she began to recognise the immaturity of her faith and to grope towards a deeper understanding of Christian teaching.

\section{Interpretation}

An understanding of attitudes and feelings often comes through the patient's detailed description of a small but highly important incident. In the present case, the mother's failure at breast feeding supplies an example. In the context of increasing 'depression', it was quite clear that she experienced this failure as a personal deprivation and an attack on herself by the baby. The theory of projective identification ${ }^{5}$ is helpful in understanding this distorted perception and merits brief description.

The very young infant experiences strong feelings of love and hate directed towards the same object (initially the mother). Since they are directed towards the same object, the feelings are conflicting. This is most difficult to tolerate and the infant's coping capacity is overwhelmed. In adults the 
coping capacity is much developed but in troubled people (such as the mother) under great stress, the coping mechanism reverts to its infantile form. One way the infant, and the troubled adult, copes is to disown the feelings of hate, attributing them to the object of the ambivalence and experiencing them as directed towards the self. This is the origin of the evil witches and wicked stepmothers of fairy stories. By an inversion of roles, mother experienced her daughter as the threat. Mother, as baby, is deprived by the malevolent will of her infant as fantasy mother. This mechanism is common in child abusers and is eloquently described by Kempe and Kempe ${ }^{6}$ ... 'to these parents "cannot" in the child is interpreted as "will not",

Other influences also helped to shape the mother's behaviour, particularly the family culture of excessive illness behaviour and the effect of the hospital environment in relieving her 'depression' and acting as a prop to her self esteem.

The therapist's tasks were to uncover and interpret these fantasies and behaviours to the patient.

Therapeutic relationship. Central to therapy is the understanding of the patient's feelings about the therapist. She said she found the therapist a consistent figure in an otherwise unreliable world. The therapist assumed that these positive feelings would be accompanied by a dark foil of negative feelings as in her other relationships. Throughout therapy, however, and despite interpretation, these negative feelings never surfaced.

Role of father. The father was not included in the therapy sessions but played a key part in the rehabilitation process. From being a somewhat passive figure in the family, he responded positively to the family crisis and became more involved in family life and an essential support to his wife. At the end of therapy, he told the social worker that the discovery of the abuse had been the best thing that had happened to his family because his wife then got the help she so obviously needed. Family life seemed generally to have become closer and more enriched.

Changes in therapy. A major problem with therapy in Munchausen syndrome by proxy is that the therapist is reliant on the patient telling the truth. There seemed reasonable collateral evidence, however, for the following changes:

(1) Further abuse had not occurred and mother's care of all her children had not given rise to concern over a 15 month follow up period from confession.
(2) There had been a cessation of her abnormal illness behaviour.

(3) There were changes in her attitude to her religion. Less censorious and severe and more informed by her own humanity.

(4) During therapy, she was able to become more firm in her management of her father.

(5) While never a very demonstrative person, it was felt that she became generally warmer and more spontaneous socially.

(6) Despite the pain of the events, the mother said that she was glad that she had been found out so that she could get the help she needed.

\section{Conclusions}

Most of the therapies advocated for child abuse are aimed either at general support ${ }^{6}$ or at the correction of obviously abnormal observable behaviour. Quite often, however, abuse is perpetrated by a parent whose behaviour seems motivated by severe neurotic conflicts but who seems otherwise well socialised. The form of abuse in these cases is not always Munchausen syndrome by proxy but may be sexual, emotional, or even physical abuse. Individual interpretive psychotherapy may have a place in this minority of cases, and where the patient is reasonably well motivated in trying to confront his or her difficulties, is of average intelligence, and not beset with family and social problems. The primitive denial and projection of feelings shown in this case are common and need forceful intervention. Appearance as an expert witness in court provides an excellent opportunity to set the stage.

\section{References}

' Hutchings J. The behavioural approach to child abuse. In: Finde N, ed. Psychological approaches to child abuse. London: Batsford, 1980:181-91.

2 Nicol AR, Mearns C, Hall D, Kay B, Williams B, Akister J. An evaluation of focused casework in improving interaction in abusive families. In: Stevenson J, ed. Recent research in developmental psychopathology. Oxford: Pergamon, 1985.

${ }^{3}$ Novaco R. Anger control: the development and evaluation of an experimental treatment. Lexington, Mass: Heath and Co, 1975.

${ }^{4}$ Meadow R. Factitious illness- the hinterland of child abuse. In: Meadow R, ed. Recent advances in paediatrics No. 7. Edinburgh: Churchill-Livingstone, 1984:217-32.

${ }^{5}$ Segal H. Introduction to the work of Melanie Klein. London: Heinemann, 1964.

${ }^{6}$ Kempe RS, Kempe CH. Child abuse. London: Fontana/Open Books, 1978.

Correspondence to $\operatorname{Dr}$ A R Nicol, Nuffield Psychology and Psychiatry Unit, Fleming Memorial Hospital, Newcastle upon Tyne NE2 3AX.

Received 4 September 1984 